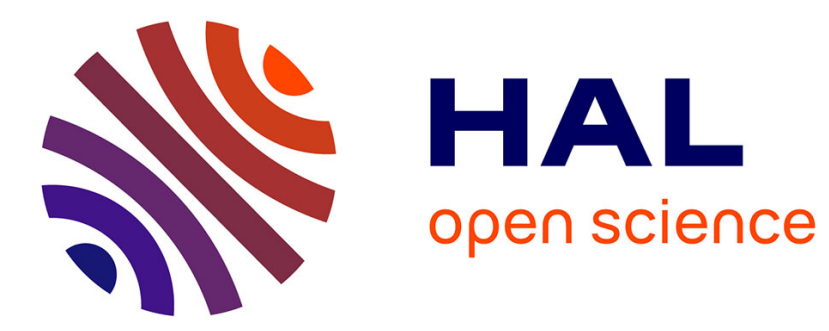

\title{
Laser-driven shocks to explore the effects of aging on the adhesion of silver sintered on copper substrate
}

\author{
T. de Resseguier, X Milhet, V Labussière, E Barraud, L Signor, J Baillargeat
}

\section{To cite this version:}

T. de Resseguier, X Milhet, V Labussière, E Barraud, L Signor, et al.. Laser-driven shocks to explore the effects of aging on the adhesion of silver sintered on copper substrate. Journal of Adhesion Science and Technology, 2021, pp.1 - 18. 10.1080/01694243.2021.1970396 . hal-03426310

\section{HAL Id: hal-03426310 https://hal.science/hal-03426310}

Submitted on 12 Nov 2021

HAL is a multi-disciplinary open access archive for the deposit and dissemination of scientific research documents, whether they are published or not. The documents may come from teaching and research institutions in France or abroad, or from public or private research centers.
L'archive ouverte pluridisciplinaire HAL, est destinée au dépôt et à la diffusion de documents scientifiques de niveau recherche, publiés ou non, émanant des établissements d'enseignement et de recherche français ou étrangers, des laboratoires publics ou privés. 


\title{
Laser-driven shocks to explore the effects of aging on the adhesion of silver sintered on copper substrate
}

\author{
T. de Rességuier, X. Milhet, V. Labussière, E. Barraud, L. Signor, J. Baillargeat \\ Institut Pprime, UPR 3346, CNRS, ISAE-ENSMA, Université de Poitiers, Futuroscope \\ Cedex, FRANCE
}

This is an Accepted Manuscript of an article published by Taylor \& Francis in the Journal of Adhesion Science and Technology on September 2, 2021, available online:

https://doi.org/10.1080/01694243.2021.1970396

\begin{abstract}
The adhesion of thin silver joints sintered on metallic substrates is a major issue for their potential use in power electronics modules. Here, we explore how laser shock-induced spallation can provide a way to study this adhesion. Due to wave interactions inside the shock-loaded assembly, dynamic tensile stresses are induced near the copper-silver interface, resulting in partial or full removal of the silver layer. In order to investigate the effects of aging on the interface strength, experiments are performed on both as-sintered and aged samples. Time-resolved measurements of the free surface velocity provide information on wave dynamics and interface failure, but finite-element simulations show that inferring a quantitative value of the bonding strength from these data is still challenging. Nevertheless, post-recovery observations provide original insight into the debonding process, including some complex effects of aging, consistent with trends reported in the literature.
\end{abstract}

Keywords : interface strength, laser shocks, sintered silver, spallation

\section{Introduction}

Advanced power electronics modules are built by stacking up layers of various materials. In particular, sintered silver (Ag) pastes are regarded as excellent candidates for bonding chips onto the substrate since Ag has a high melting temperature with superior electrical and thermal conductivities over current solutions [1-6]. However, because the constituents have different coefficients of thermal expansion, both tensile and compressive stresses are expected to develop within the various layers in operating conditions. Besides, both the Ag film and the interface suffer aging, mostly related to diffusion within the porous Ag itself and/or at the interface with the substrate [2,3]. All of these might alter the adhesion of the chip, compromising the entire power module reliability. Thus, there is a crucial need for testing the adhesion of these particular interfaces and for understanding its potential evolution with aging.

Adhesive strength of sintered Ag joints is usually evaluated using the Die Shear test $[1,2,5,6]$, where the loading pattern and specimen geometry (typically substrate / joint / dummy 
chip) are somewhat complex. An alternative technique based on laser shock loading has been proposed since a few decades to test the adhesion at an interface between a substrate and a coating (see e.g. refs [7-15] for early work and ref. [16] with references therein for recent advances in a variety of application fields). The principle is to use the dynamics of compression and release waves inside a shock-loaded multi-layered assembly to generate a short tensile pulse near the interface to be tested. If the local tensile stress overcomes the interface strength, debonding occurs, new free surfaces are created, and subsequent stress relaxation produces recompression waves. In favorable cases, the detection of such waves in velocity records and their analysis may provide an estimate of the bonding strength at the interface [17]. This technique requires (i) planar shock loading of controlled amplitude and duration on the substrate side, (ii) accurate time-resolved measurement of the free surface velocity of the coating, opposite to the loaded spot, (iii) a correct knowledge of the materials constituting both layers, including the density and sound velocity in the coating material, and (iv) an adhesive strength at the interface lower than the cohesive strength (so-called spall strength) of these constituents.

In this paper, we investigate how this shock-based technique can be applied to evaluate the bonding strength of sintered $\mathrm{Ag}$ films deposited onto copper $(\mathrm{Cu})$ substrates. First, preliminary laser shots on $\mathrm{Cu}$ alone provide a characterization of the pressure load, then a detailed analysis of wave propagation within the $\mathrm{Cu}-\mathrm{Ag}$ assembly, including finite element simulations, indicates how the adhesive strength will affect the evolution of the free surface velocity in our configuration. Finally, experimental results combining velocity records and post-recovery observations are presented for both as-sintered and aged specimens, to explore the effects of aging on the interfacial strength.

\section{Experimental set-up}

Samples consist of a sintered Ag layer of thickness ranging from about 30 to $90 \mu \mathrm{m}$ deposited on a $\mathrm{Cu}$ plate, either 0.5 or $1 \mathrm{~mm}$-thick. Details of the processing conditions are given in [18]. The $\mathrm{Cu}$ substrate was mechanically polished until a mirror finish was obtained (using $\mathrm{SiC}$ paper grit 1000 to 4000 followed by diamond polishing with $3 \mu \mathrm{m}$ then $1 \mu \mathrm{m}$ ). The Ag paste, composed with $4 \mu \mathrm{m}$-diameter particles mixed with various solvents to prevent agglomeration, was printed on the substrate, then set under low vacuum $\left(10^{-5} \mathrm{~Pa}\right)$ to evaporate the solvents, before sintering at $250^{\circ} \mathrm{C}$ for 3 min under a $10 \mathrm{MPa}$ load. Aging was performed at $220^{\circ} \mathrm{C}$ for $460 \mathrm{~h}$ and $840 \mathrm{~h}$, under the same vacuum $\left(10^{-5} \mathrm{~Pa}\right)$ to limit oxidation. The density of sintered Ag before and after aging was estimated using image analysis as described in [18]. Scanning electron microscopy was performed with a Tescan Vega 3 LM microscope in both Secondary Electron (SE) imaging and Back-Scattered Electron (BSE) imaging (well suited to distinguish between $\mathrm{Cu}$ and $\mathrm{Ag}$ ). Sections of the $\mathrm{Ag}$ film near the specimen edges provided a mean area pore fraction estimated at $15 \pm 2 \%$, for both as-sintered and aged specimens. From past analysis [18], this was found to correspond to an average density around $7.9{\mathrm{~g} . \mathrm{cm}^{-3}}^{-3} \sim 25 \%$ pore volume fraction). Aging of porous Ag was observed to create locally some larger pores (Oswald ripening mechanism) and make pore size distribution less homogeneous [19,20]. Clear differences were seen between the as-sintered samples, which exhibit a sharp interface with no oxide layer (Fig. 1a), and the aged samples, where atomic diffusion promoted a more complex interface morphology, including both $\mathrm{Ag}$ grains expanding within the $\mathrm{Cu}$ substrate and $\mathrm{Cu}$ oxide growing into $\mathrm{Ag}$, with large pores developing at the interface (Fig. 1b). 
(a)

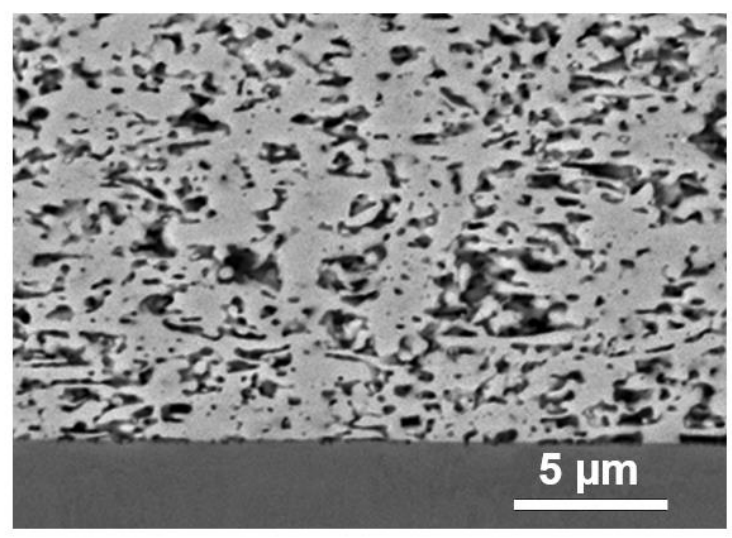

(b)

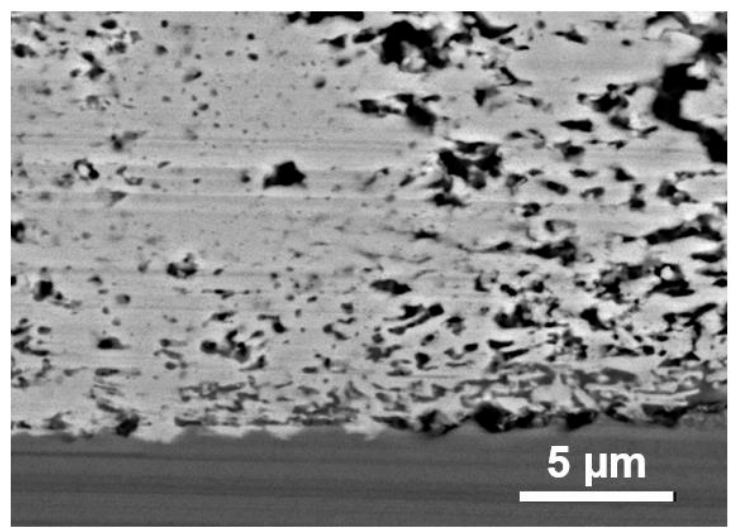

Figure 1. Typical section views in Back-Scattered Electron microscopy showing the (preshock) microstructure of the $\mathrm{Cu}$ (bottom) / $\mathrm{Ag}$ (top) interface in (a) as-sintered specimen or (b) after aging. Energy Dispersive Spectroscopy, not shown here, reveals either no (a) or extensive (b) atomic diffusion near this interface.

Shock experiments were performed at the Centre d'Utilisation des Lasers of Institut Pprime (Poitiers, France). Four specimens of each type (as-sintered, aged $440 \mathrm{~h}$ and aged 840 h) were shot (one shot per sample). A neodymium-glass (Nd:glass) laser delivers a single pulse of $1.053 \mu \mathrm{m}$-wavelength, about $30 \mathrm{~ns}$-duration (full width at half maximum, measured at each shot with a high speed photodiode) and about $15 \mathrm{~J}$ maximum energy (inferred at each shot from a small, calibrated portion of light transmitted through a mirror and measured with a Gentec calorimeter). The beam is focused on a $4 \mathrm{~mm}$-diameter spot in the $\mathrm{Cu}$ surface. The resulting laser intensity is about $4 \mathrm{GW} / \mathrm{cm}^{2}$. A thin (typically a few $\mu$ m-deep) absorbing layer of $\mathrm{Cu}$ is ablated into a plasma, and the expansion of this plasma cloud toward the laser source drives by reaction a short compressive pulse in the target (Fig. 2). Such laser-driven shocks have been routinely used for decades to investigate various aspects of the response of condensed matter subjected to dynamic loading at extreme strain rates [e.g. 21-33]. Here, to enhance both amplitude and duration of the pressure load, a water layer (a few mm-thick, pooled on top before the shot) is added above the Cu surface (Fig. 2). Since water is transparent to the laser light, the plasma is still ablated from the $\mathrm{Cu}$ plate, but its expansion is confined by the presence of this covering layer. In these conditions, peak pressure is higher and pulse duration is longer than under direct laser-matter interaction in vacuum [34,35]. However, the maximum laser intensity is then bounded below an ionization threshold above which the confining medium absorbs the laser energy (so-called laser breakdown). Assuming an approximately homogeneous energy distribution in the laser beam, the ablation pressure applied on the irradiated spot can be considered as spatially uniform. Hence, a planar compression front propagates from the loaded spot, followed by a gradual unloading wave back to ambient pressure. Because the spot diameter is much larger than the specimen thickness, lateral release waves coming from the periphery of the loaded disk do not affect the central zone over the duration of the measurement, i.e. conditions of uniaxial (1D) strain are induced in this central zone. This incident pressure pulse is transmitted into the Ag layer (see details in Section 3), then it reaches the Ag free surface (FS), which is set into motion. The velocity of this free surface is monitored using a Velocity Interferometer System for Any Reflector (VISAR) [36], in a push-pull configuration with full quadrature [37]. A continuous laser of $532 \mathrm{~nm}$-wavelength is focused on a $\sim 30 \mu \mathrm{m}$ diameter spot opposite to the centre of the loaded surface (Fig. 2). The Doppler shift in the wavelength of the light reflected by the moving surface produces fringes in the interferometer, 
and the number of fringes is proportional to the surface velocity. The velocity-per-fringe is a constant factor, which was set to $229 \mathrm{~m} / \mathrm{s}$, sufficiently higher than the expected velocity jumps to ensure that no fringe could be lost. Data were recorded at a $2.5 \mathrm{GS} / \mathrm{s}$ sampling rate after acquisition by photomultipliers of about 1 ns-rise time, which was the actual limitation for time resolution.

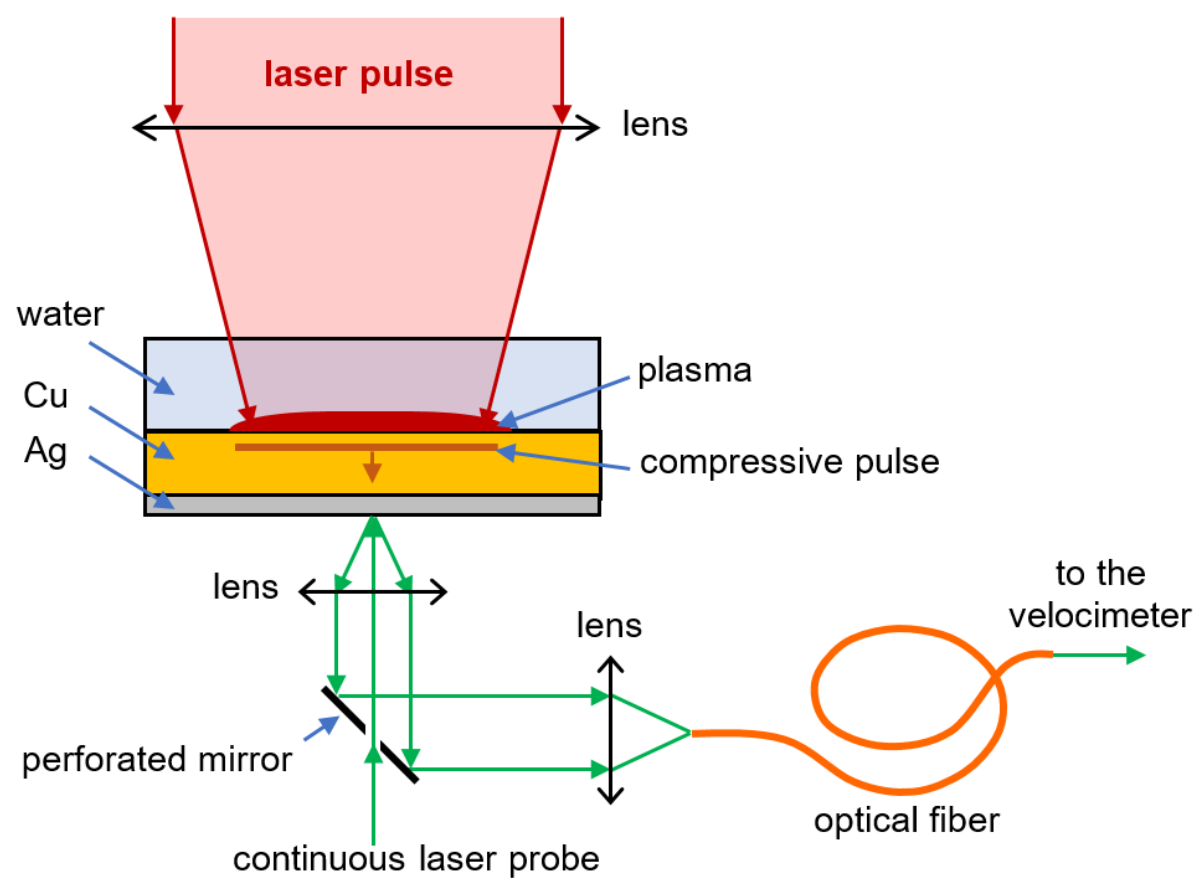

Figure 2. Schematic of the experimental setup. Upon reflection of the compressive pulse from the (bottom) free surface, tensile stresses are induced at the $\mathrm{Ag} / \mathrm{Cu}$ interface. Time-resolved measurement of the velocity of this free surface is performed with a VISAR interferometer.

\section{Preliminary analyses}

\subsection{Load calibration}

Preliminary calibration shots on $\mathrm{Cu}$ plates alone were dedicated to the characterization of the amplitude and temporal shape of the laser-generated pressure load. The set-up is the same as in Fig. 2 without the Ag layer. A typical velocity profile recorded at the free surface of a single, $0.5 \mathrm{~mm}$-thick $\mathrm{Cu}$ plate is shown in Fig. 3 (green solid line). Time origin matches the laser shot. After a transit time of about $100 \mathrm{~ns}$ through the plate thickness, the free surface is accelerated to a peak velocity of about $130 \mathrm{~m} / \mathrm{s}$ upon shock breakout, then the emergence of the unloading wave induces a gradual deceleration, followed by oscillations corresponding to wave reverberation between the loaded surface (where the plasma still exerts a decreasing pressure) and the probed free surface. Thus, the period of these oscillations is proportional to the plate thickness. 


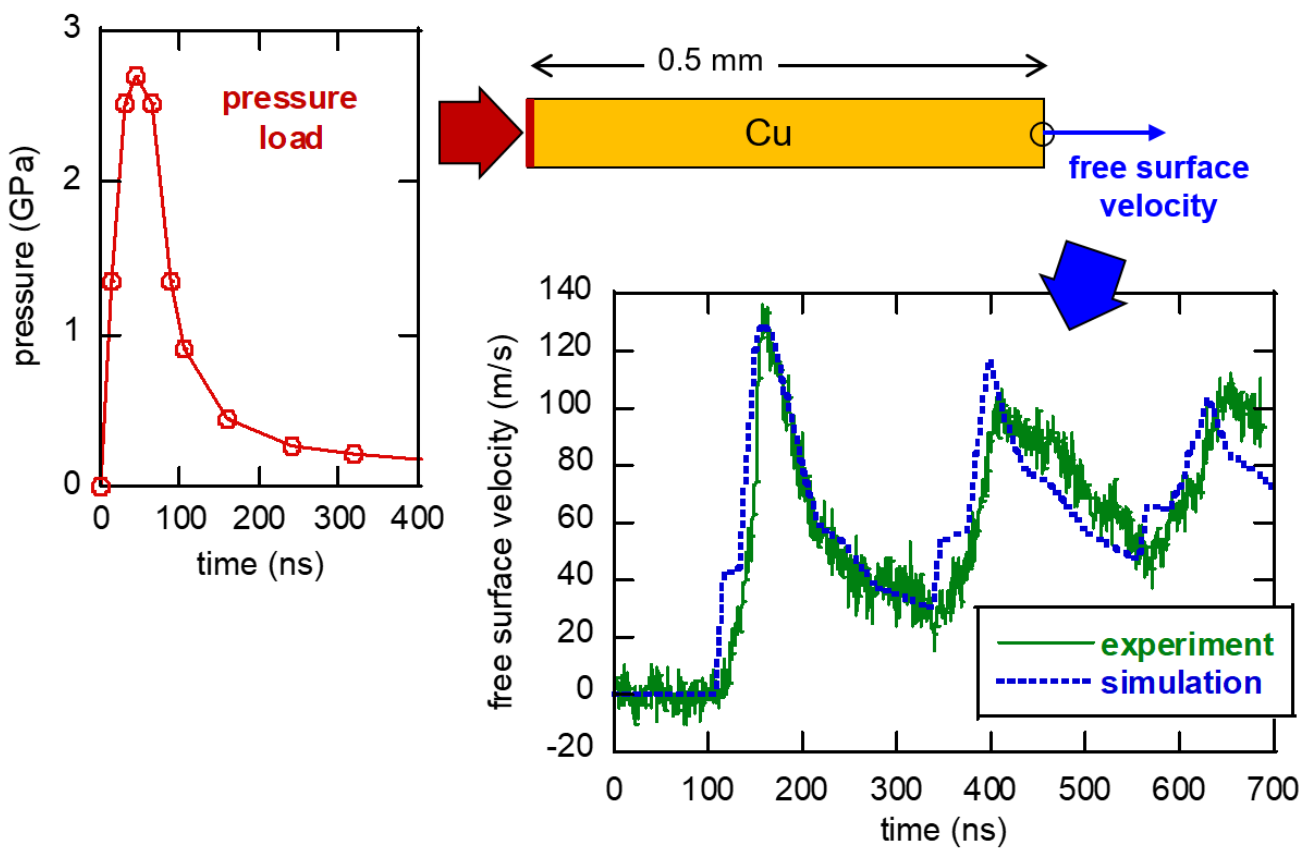

Figure 3. Typical response of a $0.5 \mathrm{~mm}$-thick $\mathrm{Cu}$ plate to a laser shock in water-confined geometry. The free surface velocity record (green solid line) is compared with the prediction of a 1D simulation (blue dotted line) using the pressure load $P(\mathrm{t})$ plotted to the left (red solid line) as a boundary condition applied on the irradiated surface. The good match between the calculated and measured profiles ensures to some extent the relevance of this pressure load for the corresponding irradiation conditions.

Numerical simulations of these calibration tests were performed with the Radioss hydrocode [38]. As stated earlier (Section 2), 1D strain is imposed assuming longitudinal propagation of planar waves in the central region of interest. Material behavior is classically described with an elastic-perfectly plastic constitutive law and a Mie-Grüneisen equation of state $[39,40]$. The pressure pulse plotted to the left in Fig. 3 (red solid line) results from an inverse identification detailed next. It is applied as a boundary condition on the loaded side of the $\mathrm{Cu}$ specimen, discretized into 1000 finite elements, fine enough to capture the steep gradients associated with shock waves. The calculated profile of the free surface velocity (blue dotted line) is compared with the VISAR record (green solid line), and the input pressure pulse is adjusted until obtaining a good match between computed and measured velocity profiles. The wave fronts split into an elastic precursor followed by a slower plastic wave, leading to a socalled two-wave structure which is found to be much more pronounced in the computation than in the record, because of the rough description of the elastic-plastic response of $\mathrm{Cu}$. Despite this minor discrepancy, a good overall match is obtained, which assesses that both the amplitude and temporal shape of the pressure profile are a good representation of the laser-driven compression. In the presence of a confining layer, the duration of this pressure load is consistently much longer than that of the laser pulse. The peak pressure of $2.7 \mathrm{GPa}$ resulting from a laser intensity of $4 \mathrm{GW} / \mathrm{cm}^{2}$ in water-confined interaction is in very good agreement with similar data reported in the literature [35].

Loading pulses inferred from the calibration method above (using single $\mathrm{Cu}$ plates) can be applied to $\mathrm{Cu}-\mathrm{Ag}$ targets subjected to the same conditions of laser irradiation as long as no reflected perturbation (either from the $\mathrm{Cu}-\mathrm{Ag}$ interface or from the Ag free surface) propagate back into the plasma. This condition is met in all our experiments over the time of interest (i.e. well after tensile loading and potential debonding at the substrate-coating interface). 


\subsection{Relation between bonding strength and free surface velocity}

Our experiments include time-resolved measurements of the Ag free surface velocity. In this subsection, a preliminary study, both analytical and numerical, shows why and how such velocity records do depend on the interface bonding strength, but also how they are affected by other parameters such as the Ag thickness, so that inferring a quantitative strength value is not trivial. First, a phenomenological analysis of the propagation and interactions of pressure waves in the $\mathrm{Cu}-\mathrm{Ag}$ assembly is illustrated in Fig. 4.

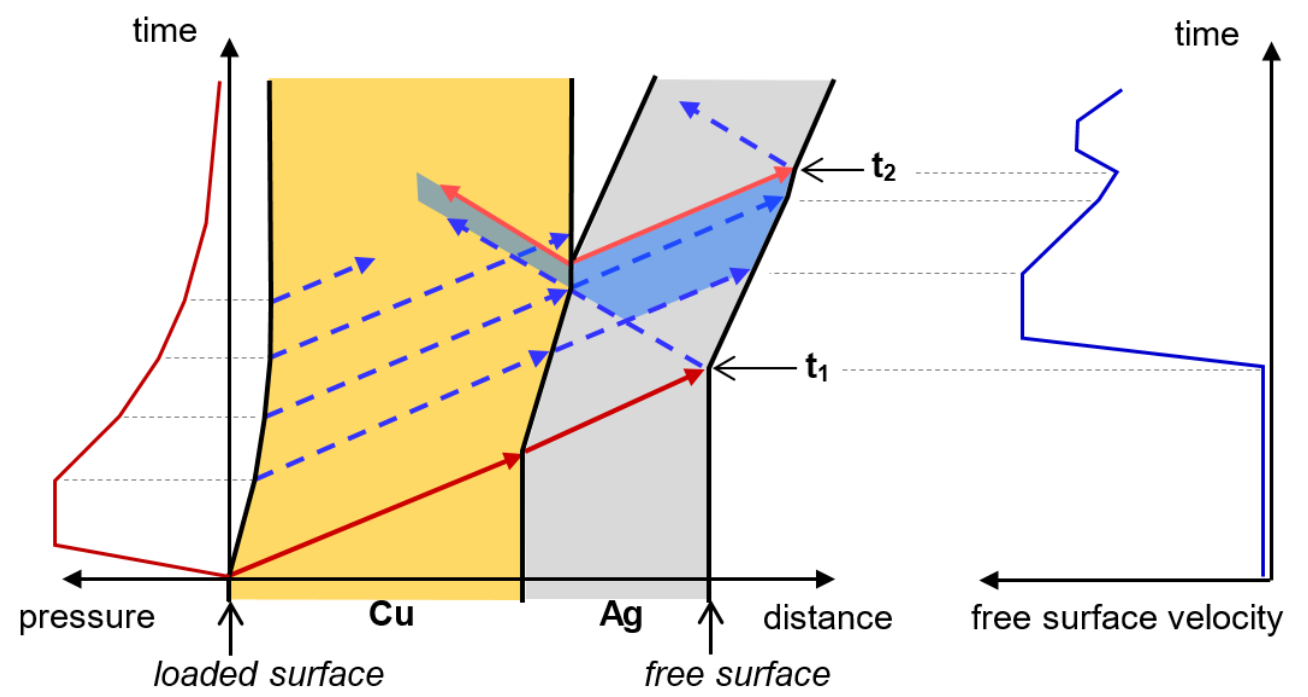

Figure 4. Schematic description of wave propagation in a Cu-Ag sample subjected to a laserdriven pressure load on its left surface (see text for details).

The pressure load $\mathrm{P}(\mathrm{t})$ resulting from laser ablation (Section 3) is imposed on the left surface of the $\mathrm{Cu}$ plate. It starts with a steep compression which propagates from this surface toward the $\mathrm{Cu}-\mathrm{Ag}$ interface (solid red arrow). The transmission across this interface is governed by the so-called acoustic impedance of both constituents, i.e. the product $\rho_{0} C_{0}$ of their density and bulk sound velocity [39]. As reported in Table I, $\mathrm{Cu}$ and (dense) Ag have very close impedances, which is a favorable condition, since the incident pulse is then merely transmitted into the Ag layer, with essentially no wave reflection in the $\mathrm{Cu}$ substrate. However, the porosity of the Ag layer may significantly lower its impedance. After propagation throughout the coating, the compressive front is reflected from the Ag free surface (time $t_{1}$ ) into a rarefaction wave (dashed blue arrow) back to ambient pressure. Meanwhile, an unloading wave following the compression front propagates from the loaded side. It is initially more gradual than the compression (Fig. 4), and it spreads further during its propagation because of the variation of sound speed with pressure, so it becomes a progressive, continuous release, represented schematically as a succession of dashed blue, right-oriented arrows. As will be shown next, thicknesses were chosen so that this incident release wave meets the reflected rarefaction wave near the $\mathrm{Cu}-\mathrm{Ag}$ interface. Their interaction induces tensile stresses (negative pressure, in the blue-coloured region), which would cause fracture inside a bulk sample, referred to as spall fracture and extensively studied in shock physics [e.g. 21,23,25-27,30,31,33,41,42]. Here in a two-layered sample, if the tensile loading overcomes the adhesive strength $\sigma_{\text {int }}$, it causes interface debonding, thus creating new free surfaces. Subsequent relaxation of the local tension generates recompression waves (red arrows), and the one propagating in Ag reaccelerates the free surface (time $t_{2}$ ). Thereafter, if the detached Ag layer remains unbroken, one may expect velocity oscillations associated with wave reverberation across this layer. 
Table I. Density, bulk sound speed and acoustic impedance of $\mathrm{Cu}$ and dense $\mathrm{Ag}$

\begin{tabular}{|c|c|c|c|}
\hline & $\begin{array}{c}\text { density } \rho_{0} \\
\left(\mathrm{~g} / \mathrm{cm}^{3}\right)\end{array}$ & $\begin{array}{c}\text { bulk sound speed } C_{0} \\
(\mathrm{~km} / \mathrm{s})\end{array}$ & $\begin{array}{c}\text { acoustic impedance } \rho_{0} C_{0} \\
\left(\mathrm{~g} / \mathrm{cm}^{2} . \mu \mathrm{s}\right)\end{array}$ \\
\hline $\mathrm{Cu}$ & 8.93 & 3.94 & 3.52 \\
$\mathrm{Ag}$ & 10.49 & 3.23 & 3.39 \\
\hline
\end{tabular}

Fig. 5 shows a 1D simulation of pressure wave propagation in a two-layered target consisting of a $0.5 \mathrm{~mm}$-thick $\mathrm{Cu}$ substrate coated with a $50 \mu \mathrm{m}$-thick Ag layer. In this preliminary approach, $\mathrm{Ag}$ is modelled as a dense material, i.e. the effects of porosity are not accounted for, which will be discussed later, and the $\mathrm{Cu}-\mathrm{Ag}$ interface is modelled as a specific

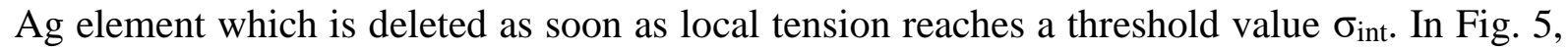
this value is chosen as $500 \mathrm{MPa}$, because it will be the order of magnitude suggested by our measurements (see Section 4). Further, it will be increased to $900 \mathrm{MPa}$ to illustrate its influence on the velocity profile, then to $1 \mathrm{GPa}$ to switch to a case without debonding. The same pressure load $P(t)$ as in Fig. 3 is applied as an input boundary condition onto the left surface. The compressive pulse propagates to the right $(\mathrm{a}, \mathrm{b})$, is transmitted across the interface with essentially no reflected perturbation, the shock front reflects from the free surface into a leftpropagating rarefaction wave (c), and its later interaction with the incident unloading wave (d) induces tension (negative pressure, dark blue). As mentioned earlier, the duration of the pressure load and the thicknesses of both layers are well suited to ensure a tensile load near the interface to be tested. Finally, when tension reaches the prescribed interface strength $\sigma_{\text {int }}(500$ $\mathrm{MPa}$ ), debonding occurs at about $180 \mathrm{~ns}$ (e), creating new free surfaces and subsequent stress relaxation to ambient pressure (pale blue). Thereafter, waves reverberate through the detached $\mathrm{Ag}$ layer (f) while further tension is induced deeper inside the $\mathrm{Cu}$ plate.

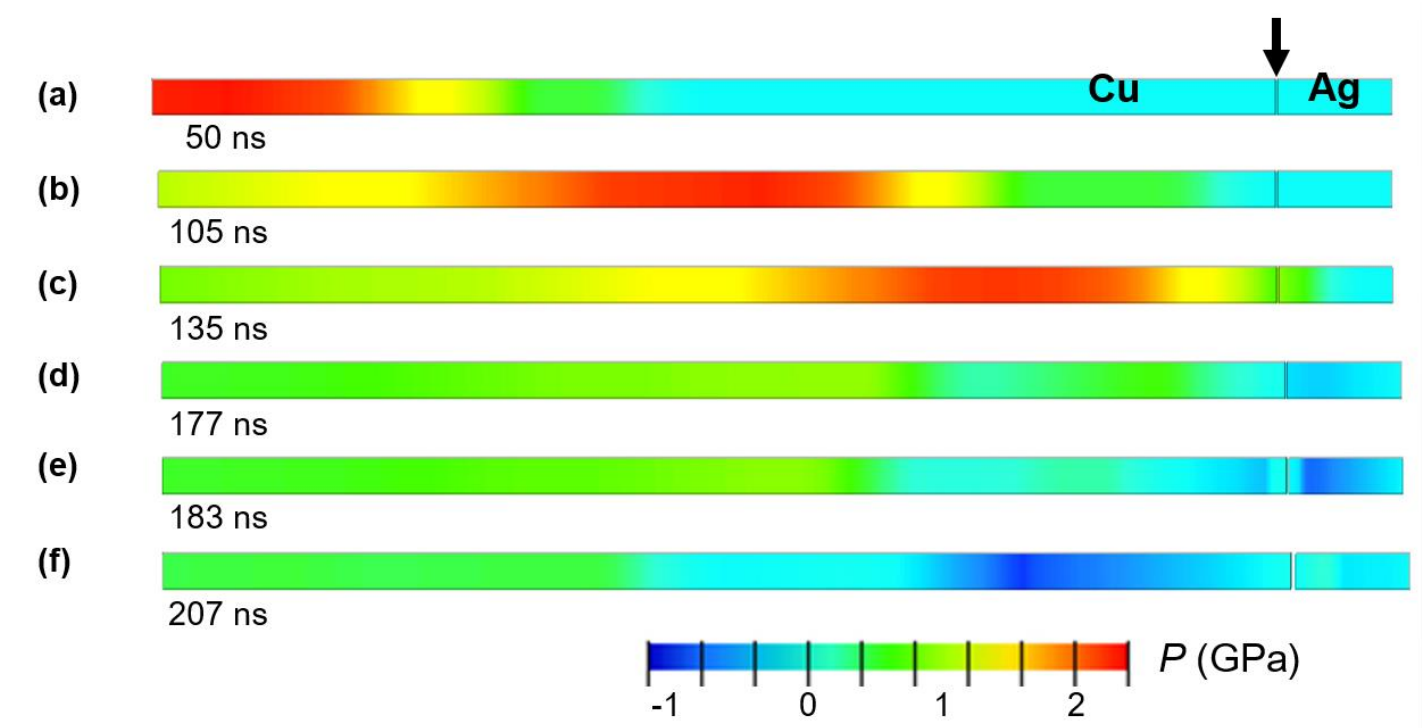

Figure 5. Simulation of 1D wave propagation in a $\mathrm{Cu}-\mathrm{Ag}$ sample subjected to a laser-driven pressure load on its left surface. The Cu plate is $0.5 \mathrm{~mm}$-thick (horizontal length) and the $\mathrm{Ag}$ coating is $50 \mu \mathrm{m}$-thick, the arrow points to the initial position of the interface. Pressure contours are plotted at successive times after the laser shot. The interface strength under dynamic tension was chosen as $500 \mathrm{MPa}$. 
In Fig. 6, the velocity of the Ag free surface in the simulation above (where $\sigma_{\text {int }}=500$ $\mathrm{MPa}$ ) is compared with two similar simulations with higher values of the adhesive strength. When $\sigma_{\text {int }}=1 \mathrm{GPa}$, the interface resists the tensile load, so that no debonding occurs (unlike in Fig. 5). The free surface velocity profile exhibits slow oscillations corresponding to wave reverberation throughout the whole sample thickness $(\mathrm{Cu}+\mathrm{Ag})$, similar to Fig. 3 (Cu alone). When $\sigma_{\text {int }}=500 \mathrm{MPa}$, the velocity profile is identical until the interface fails (at about $180 \mathrm{ns,}$ see Fig. 5). Then, the gradual deceleration is interrupted by the arrival at the free surface of the relaxation wave generated by interface debonding. Thereafter, fast oscillations are observed, due to wave reverberation through the Ag layer alone $(50 \mu \mathrm{m})$, i.e. between the newly created free surface at the interface and the outer surface. This is qualitatively consistent with the analytical description (Fig. 4). In principle, the so-called "velocity pullback" $\Delta u$ between the peak velocity and the first reacceleration should be sensitive to the value of the interface

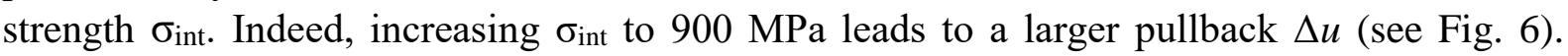
Following a simple, so-called acoustic approximation, and assuming that the thickness of the coating and the duration of the loading pulse are ideally combined to ensure that maximum tension is induced exactly at the interface location, a rough estimate of the interfacial strength would be

$$
\sigma_{\text {int }} \approx 1 / 2 \rho_{\mathrm{Ag}} C_{\mathrm{Ag}} \Delta u
$$

where $\rho_{\mathrm{Ag}}$ and $C_{\mathrm{Ag}}$ are the density and bulk sound velocity in the Ag layer, respectively [17]. Using the Ag parameters in Table I and $\Delta u=38 \mathrm{~m} / \mathrm{s}$ inferred from the first velocity profile, one would obtain $\sigma_{\text {int }} \approx 640 \mathrm{MPa}$. This analytical approximation is higher than the $500 \mathrm{MPa}$ value used in the simulation, which indicates the limits of the simplistic assumptions above. In practice, in our case of a loading pulse of approximately triangular shape, tension increases gradually within the Ag layer between its free surface and the interface with $\mathrm{Cu}$. Therefore, the peak tensile stress induced at this interface will increase with the Ag thickness. In Fig. 7, the solid-line profile (500 MPa) from Fig. 6 is compared with a similar simulation where $\sigma_{\text {int }}$ is still $500 \mathrm{MPa}$, but where the thickness of the Ag layer was reduced from $50 \mu \mathrm{m}$ to $30 \mu \mathrm{m}$. The $\Delta u$ value is then found to decrease to $30 \mathrm{~m} / \mathrm{s}$, because the interface is not subjected to the same tensile load, as stated above. Hence, in our experimental configuration involving a roughly triangular pressure pulse and some variations of the Ag layer thickness between different samples due to the sintering process, the velocity pullback $\Delta u$ does not directly provide the adhesive strength at the interface. 


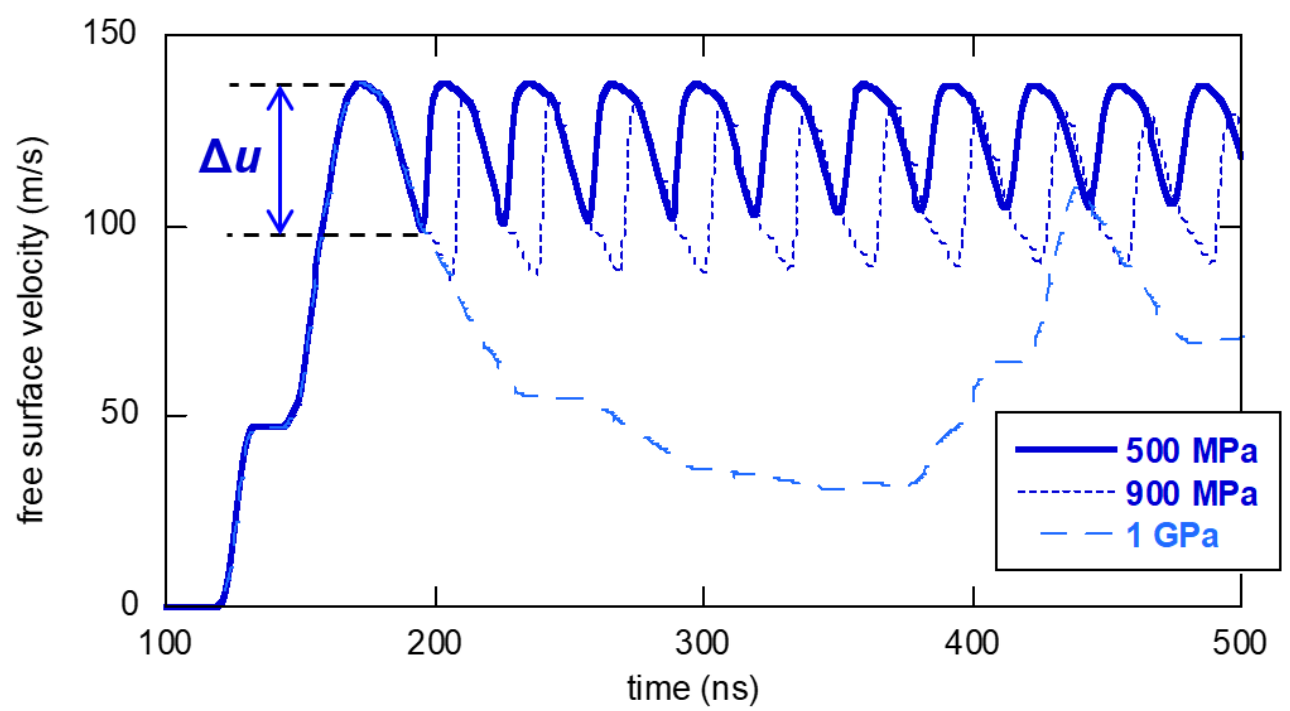

Figure 6. Simulation of the free surface velocity at the back of a $50 \mu \mathrm{m}$-thick Ag layer coated on a $0.5 \mathrm{~mm}$-thick $\mathrm{Cu}$ plate with an adhesive strength $\sigma_{\text {int }}$ of $500 \mathrm{MPa}$ (solid line, same computation as in Fig. 5), compared with similar computations with $900 \mathrm{MPa}$ (dotted line) and $1 \mathrm{GPa}$ (dashed line, where no debonding occurs).

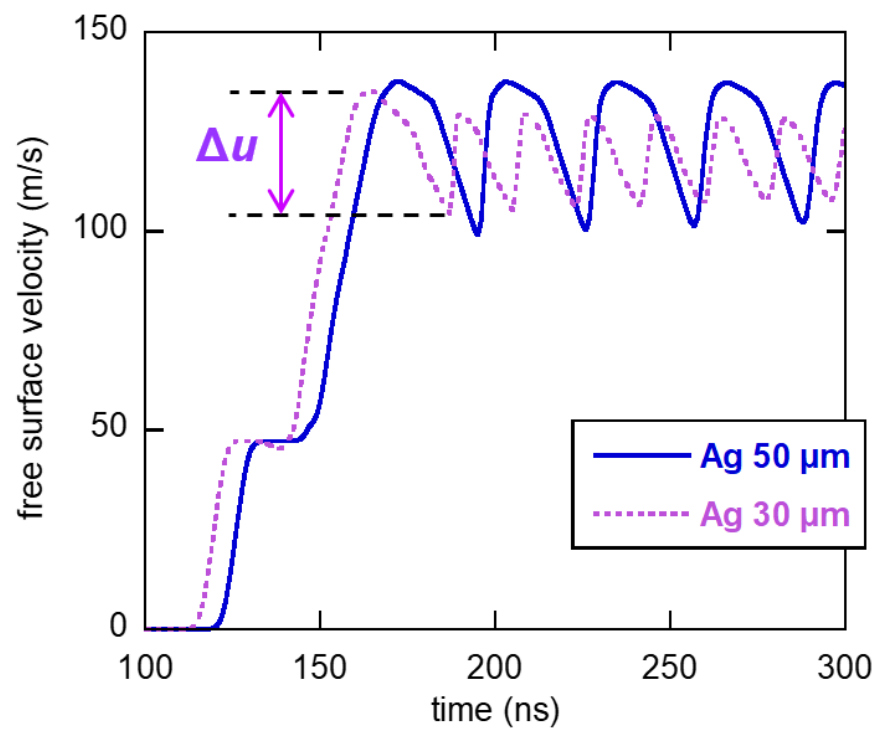

Figure 7. Simulation of the free surface velocity behind a $50 \mu \mathrm{m}$-thick Ag layer coated on a 0.5 mm-thick Cu plate with an adhesive strength $\sigma_{\text {int }}$ of $500 \mathrm{MPa}$ (same as in Fig. 6), compared with a similar computation with a $30 \mu \mathrm{m}$-thick Ag layer, where the $\Delta u$ value is lower although the interface strength is unchanged.

\section{Results and discussion}

\subsection{As-sintered samples}

Two VISAR records of the free surface velocity measured in $50 \mu \mathrm{m}$-thick Ag layers sintered on $0.5 \mathrm{~mm}$-thick $\mathrm{Cu}$ plates are plotted in Fig. 8. To illustrate the effects of porosity, not accounted for in the model, Fig. 9 shows a comparison of the record in Fig. 8a with a simulation 
shown in Fig. 6. The surface acceleration upon shock breakout starts later than in the computed profile, it is more gradual (i.e. the rise time is longer), and the peak velocity is much lower. These three features are consistent with the known influence of porosity on wave propagation, namely a lower sound speed, a spreading of the compression front during its propagation, and a faster pressure decay with propagation distance [43]. Thus, initial porosity of the Ag layer, pore collapse upon dynamic compression and subsequent dissipation must be accounted for to better simulate the experiment. As explained in Section 4, interface debonding should interrupt the first deceleration (see Fig. 6). Such slight interruption is seen in the record (at about $300 \mathrm{~ns}$ in Fig. 8a). It might be attributed to debonding, with discrepancies in time mainly due to porosity, as mentioned above. However, the same record also clearly exhibits a re-acceleration (at about $400 \mathrm{~ns}$ ) due to reloading after wave reverberation through the whole sample thickness $(550 \mu \mathrm{m})$, which would correspond to the case without debonding (Fig. 6). This apparent contradiction may indicate partial debonding over the probed region, with enough crack opening to provide significant stress relaxation, but enough contact remaining to allow further wave transmission across the interface. Alternatively, it may also suggest a rapid breakup of the Ag layer after removal, so that the end of the record would result from a combination of the velocities of $\mathrm{Ag}$ fragments and that of the $\mathrm{Cu}$ surface behind (explaining the late reacceleration). From the velocity pullback $\Delta u$ of about $93-53=40 \mathrm{~m} / \mathrm{s}$ (Fig. 8a) and the simplistic relationship recalled as Eq. 1 (Section 4), using the average density $\rho_{0} \approx 7.9 \mathrm{~g} / \mathrm{cm}^{3}$ of sintered Ag (Section 2) and the sound speed of dense Ag as a rough, upper bound approximation, the corresponding strength would be $\sigma_{\text {int }} \approx 500 \mathrm{MPa}$. This is fully consistent with the 370-700 $\mathrm{MPa}$ range reported for laser-spallation measurements of the interfacial strength between $\mathrm{Cu}$ pads and solder joints [14]. Such values are about ten times higher than typical values reported under quasi-static conditions [e.g. 2,44], which could be attributed to rate effects. Likewise, the spall strength of metals is typically a few GPa [42], higher by about one order of magnitude than their tensile strength measured under quasi-static loading. However, as explained in Section 4 , the $\Delta u$ value should not be used directly to evaluate the interface strength, which would require further simulations accounting for porosity and dynamic compaction, beyond the scope of this paper.

In the shot shown in Fig. 8b, laser breakdown occurred within the confining water layer, due to some hot spot in the laser beam or some impurity in the water drop, which resulted in a lower shock loading pressure. Hence, the peak velocity is about half that in Fig. 8a, and the shape of the record matches the case without debonding, i.e. slow oscillations corresponding to wave reverberation through the $\mathrm{Cu}-\mathrm{Ag}$ assembly. Indeed, post-recovery observation of the corresponding sample (see the BSE micrograph in the inset) confirms that the $\mathrm{Cu}$ - $\mathrm{Ag}$ interface has remained intact, except for some incipient decohesion in very few local zones, suggesting that the load was close to the debonding threshold conditions.

Free surface velocity profiles also provide an estimate of the strain rate just before spall fracture [e.g. 30,31,42], given by

$$
\dot{\varepsilon}=\frac{1}{2 C_{A g}} \frac{\Delta u}{\Delta t}
$$

where $\Delta u / \Delta t$ is the rate of the deceleration part in the records (see Fig. 8a). In our experiments, this strain rate is found to be between about $0.8 \times 10^{5}$ and $1.2 \times 10^{5} \mathrm{~s}^{-1}$. 
(a)

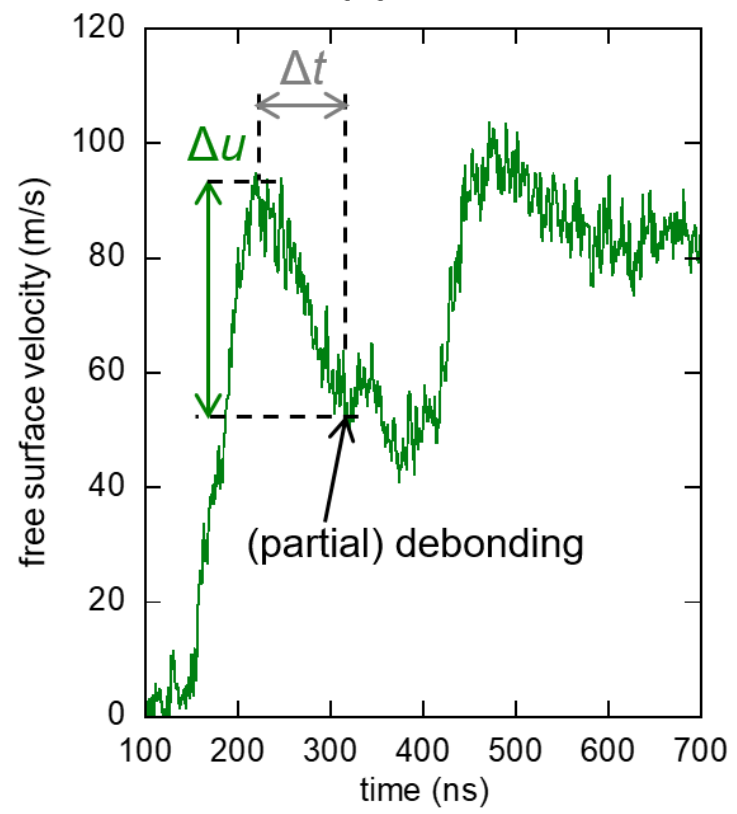

(b)

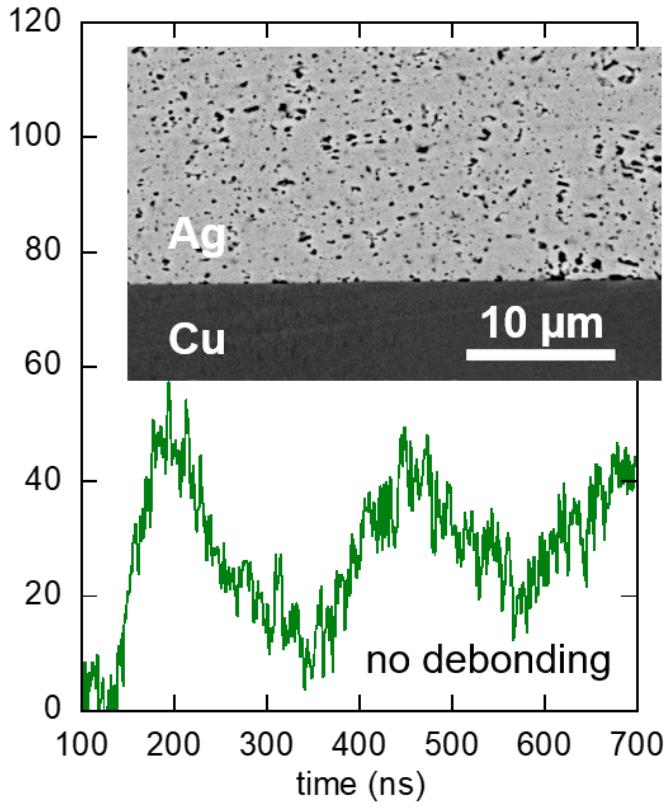

Figure 8. Free surface velocity recorded at the back of as-sintered $\mathrm{Ag}$ on $0.5 \mathrm{~mm}$-thick $\mathrm{Cu}$ plates under high (a) and low (b) shock pressure. In case (b), a back-scattered electron micrograph of a cross section in the recovered sample (inset) shows that the interface has remained essentially intact.

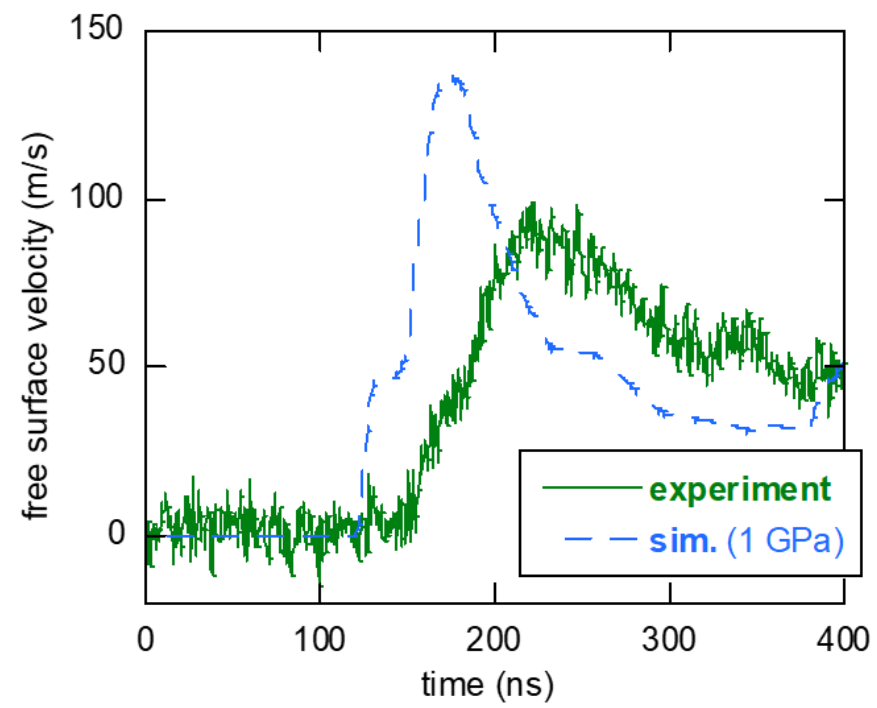

Figure 9. Comparison between the free surface velocity profile recorded behind a $\mathrm{Cu}-\mathrm{Ag}$ assembly (solid line, same as Fig. 8a) and that predicted by a simulation where the porosity of the Ag layer is ignored (dotted line, same as Fig. 6).

Fig. 10 shows a similar record behind a $30 \mu \mathrm{m}$-thick, as-sintered Ag layer coated on a 1 mm-thick $\mathrm{Cu}$ plate. Because of such thicker substrate, surface acceleration is delayed and peak velocity is lower than in Fig. 8a. Surface deceleration is interrupted at about $400 \mathrm{~ns}$, which is attributed to interface failure. No further re-acceleration by recompression waves from the loaded surface is observed in this case (over the $2 \mu$ s-duration of the measurement), which is consistent with full debonding. The lower velocity pullback $\Delta u$ of about $32 \mathrm{~m} / \mathrm{s}$ is likely due to the thinner Ag layer, as illustrated in Fig. 7, rather than to a lower resistance to tension. 


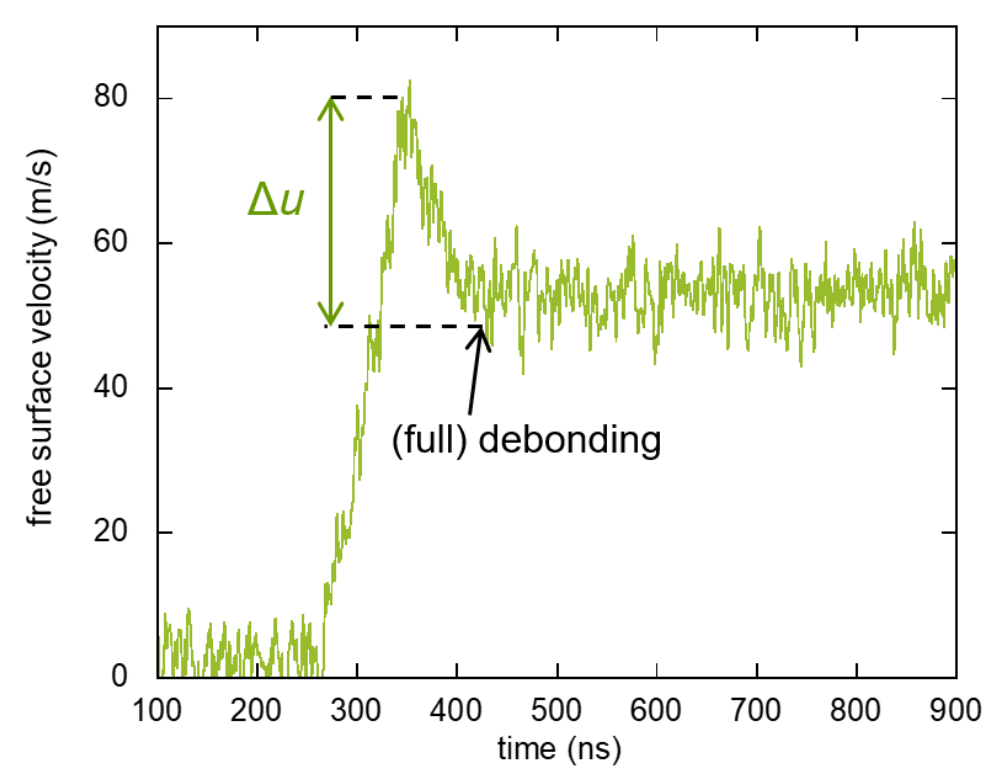

Figure 10. Free surface velocity recorded at the back of as-sintered $\mathrm{Ag}$ on a $1 \mathrm{~mm}$-thick $\mathrm{Cu}$ plate.

Post-shot observations of the coated surface (Ag-side) in the recovered sample corresponding to Fig. 10 are shown in Fig. 11. The ejection of the Ag layer after interface debonding left a circular crater slightly larger than the $4 \mathrm{~mm}$-diameter of the loaded disk in the opposite $\mathrm{Cu}$ surface (see the circle in dotted line), due to outward propagation of radial compression waves from the periphery of that loaded disk. Note that scratches in the Ag surface outside this crater result from purposely rough polishing of that surface before the shot to try to improve diffuse reflection needed for the VISAR measurement. At the bottom of this crater, about half of the surface is that of the $\mathrm{Cu}$ plate, while the other half consists of thin islets of remaining Ag (see BSE scan to the right). Actually, pre-shock examination of similar (assintered) samples viewed edge-on indicates that $\mathrm{Cu}$ and $\mathrm{Ag}$ are initially in contact over about $50 \%$ of the interface while they are separated by pores over the other $50 \%$ (Fig. 1a). This suggests that fracture under dynamic tension occurred mainly within the Ag layer just beneath the interface, so that the local adherence between $\mathrm{Ag}$ and $\mathrm{Cu}$ might be stronger than the cohesive strength of porous Ag. 

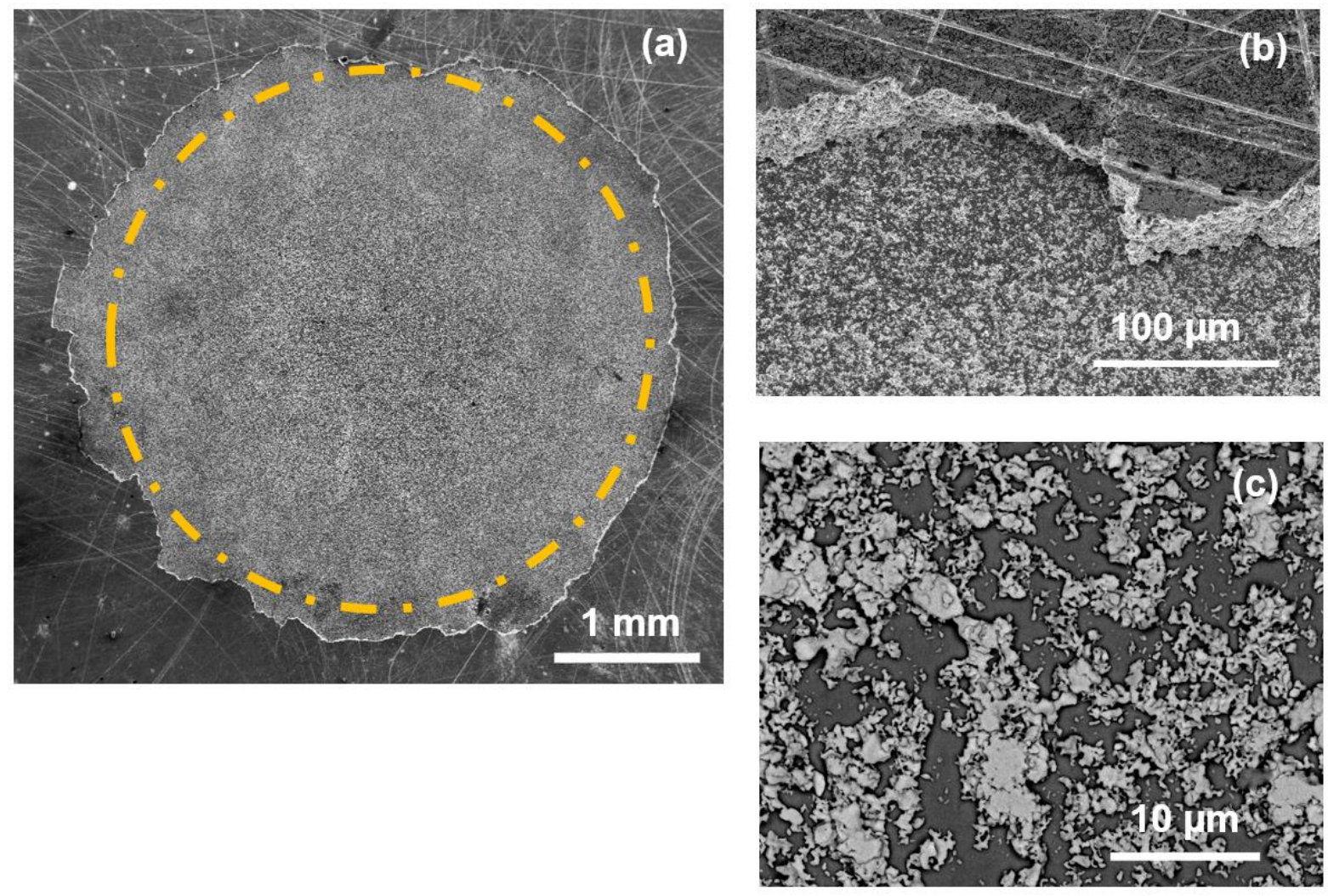

Figure 11. Scanning electron micrographs of the sample recovered after the shot corresponding to Fig. 10, showing the crater beneath the free surface resulting from the (partial) removal of a $30 \mu \mathrm{m}$-thick Ag layer (as-sintered) from a $1 \mathrm{~mm}$-thick Cu plate. The broken line in the broad view (a) corresponds to a $4 \mathrm{~mm}$-diameter circle recalling the size of the loaded spot in the opposite surface. A closer view from a $\sim 30^{\circ}$ tilt angle shows the crater edge (b), and a Back-Scattering Electron scan inside the crater (c) shows that the fracture surface consists of $\mathrm{Cu}$ (dark areas) partially covered with Ag remains (pale areas).

\subsection{Aged samples}

Fig. 12 shows VISAR records behind $50 \mu \mathrm{m}$-thick Ag layers sintered on $1 \mathrm{~mm}$-thick Cu plates and aged at $220{ }^{\circ} \mathrm{C}$ during $460 \mathrm{~h}$ (a) or $840 \mathrm{~h}$ (b) before being subjected to laser shocks. Again, a slight reacceleration of the free surface during unloading probably indicates interface debonding. The $\Delta u$ values of about $50 \mathrm{~m} / \mathrm{s}$, a bit larger than in Fig. 8 a for similar Ag thickness, might suggest a slightly higher interface adhesion, but such interpretation is still questionable as pointed out earlier. 
(a)

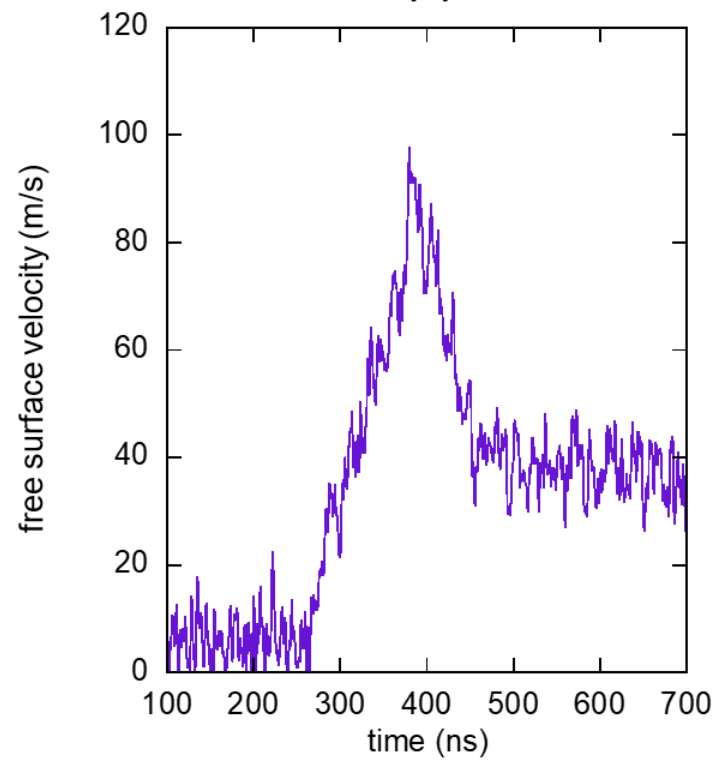

(b)

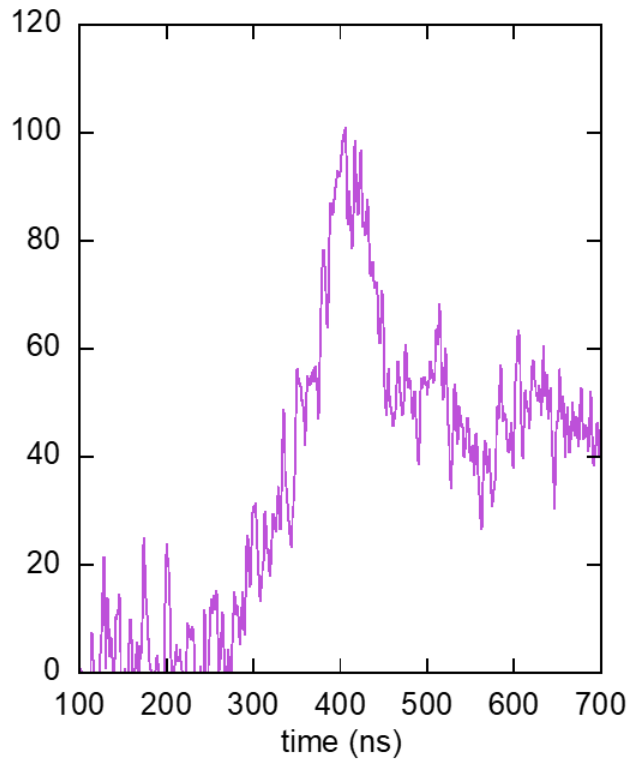

Figure 12. Free surface velocity recorded at the back of $50 \mu \mathrm{m}$-thick Ag layers sintered on 1 $\mathrm{mm}$-thick Cu plates and aged $460 \mathrm{~h}$ (a) or $840 \mathrm{~h}$ (b) before testing.

Post-recovery observations of the sample aged 840 h, corresponding to Fig. 12b, are shown in Fig. 13. The crater resulting from the (partial) removal of the Ag layer presents a roughly circular contour on its upper-left side, matching approximately the $4 \mathrm{~mm}$-diameter spot subjected to laser shock in the opposite surface (dotted line) like in Fig. 11, but large "petals" are seen outside this circle unlike in the as-sintered case. Fracture surface at the bottom of the crater combines two very distinctive types, roughly associated with different grey levels. The paler areas, mostly inside the circular contour, are still largely covered with Ag remains, much larger than the islets observed in the as-sintered case (Fig. 11). The darker areas, essentially in the outer "petals", consist of almost pure $\mathrm{Cu}$ (as confirmed by Energy Dispersive Spectroscopy, not shown here) with pits and grooves (see Fig. 13c) which were not present in the initial $\mathrm{Cu}$ substrate. Thus, the failure behavior seems highly dependent on the spatially heterogeneous microstructure of the interface after aging (see Fig. 1b), with either (i) mostly intra-Ag fracture in zones where aging produced intergrowth of $\mathrm{Ag}$ grains and $\mathrm{Cu}$ oxide, or (ii) full removal of $\mathrm{Ag}$ from zones where large pores developed due to $\mathrm{Cu}$ diffusion to form $\mathrm{Cu}$ oxide (so-called Kirkendall effect). Local tensile strength is expected to be enhanced in the first zones (case i), where interdiffusion would provide interface anchors, which might possibly account for a high $\Delta u$ value in the velocity measurement (performed in the centre of the crater). On the contrary, adhesive strength is probably very weak along highly porous zones (case ii), which might explain extensive ejection, even from the "petals" in peripheral regions where tensile stresses were low (outside the loaded spot). 

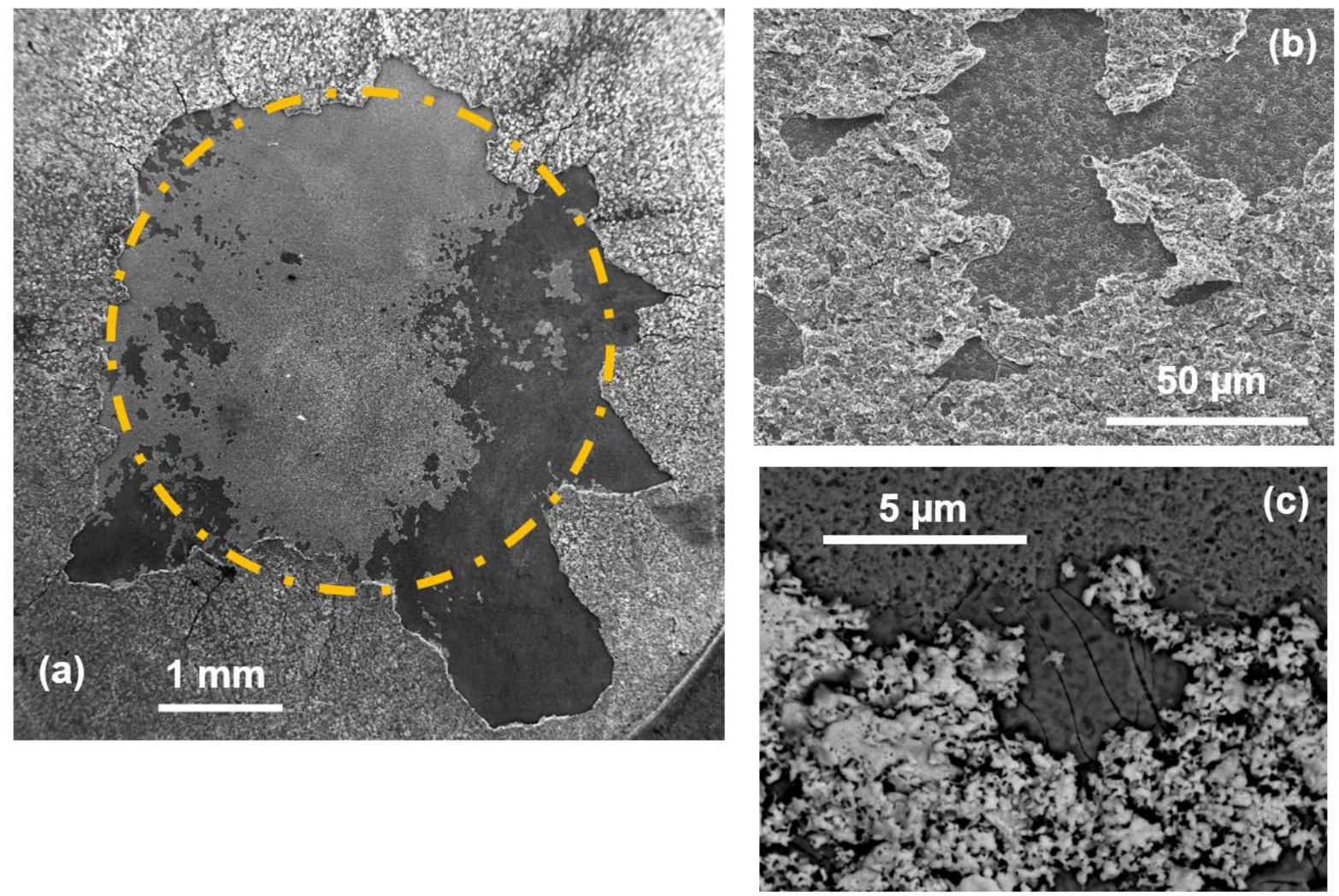

Figure 13. Scanning electron micrographs of the sample recovered after the shot corresponding to Fig. 12b, aged $840 \mathrm{~h}$ prior to laser shock loading. The crater beneath the free surface resulting from the partial removal of the $50 \mu \mathrm{m}$-thick Ag layer from the $1 \mathrm{~mm}$-thick $\mathrm{Cu}$ plate presents irregular contours, with large "petals" outside the $4 \mathrm{~mm}$-diameter circle recalling the loaded spot (a). Two types of surfaces are seen inside this crater (b, c), either naked $\mathrm{Cu}$ with pits and grooves (dark zones) or remains of $\mathrm{Ag}$ (pale areas) still attached to the substrate.

Fig. 14 illustrates similar observations for a thicker Ag layer sintered on a $1 \mathrm{~mm}$-thick $\mathrm{Cu}$ substrate, aged $840 \mathrm{~h}$ then subjected to a laser shot. In this case, most of the $90 \mu \mathrm{m}$-thick Ag layer is still present, except for a crater in the upper right part of Fig. 14a, exceeding the diameter of the loaded area like in Fig. 13. However, radial cracks are seen in the Ag surface, and section views across the loaded zone show both full separation between $\mathrm{Cu}$ and $\mathrm{Ag}$, with an open gap in-between (Fig. 14b), and locations where the interface has remained intact (left part in Fig. 14c). In these latter locations, significant diffusion of $\mathrm{Ag}$ into $\mathrm{Cu}$ is observed, which comforts the strengthening effect presumed above. 

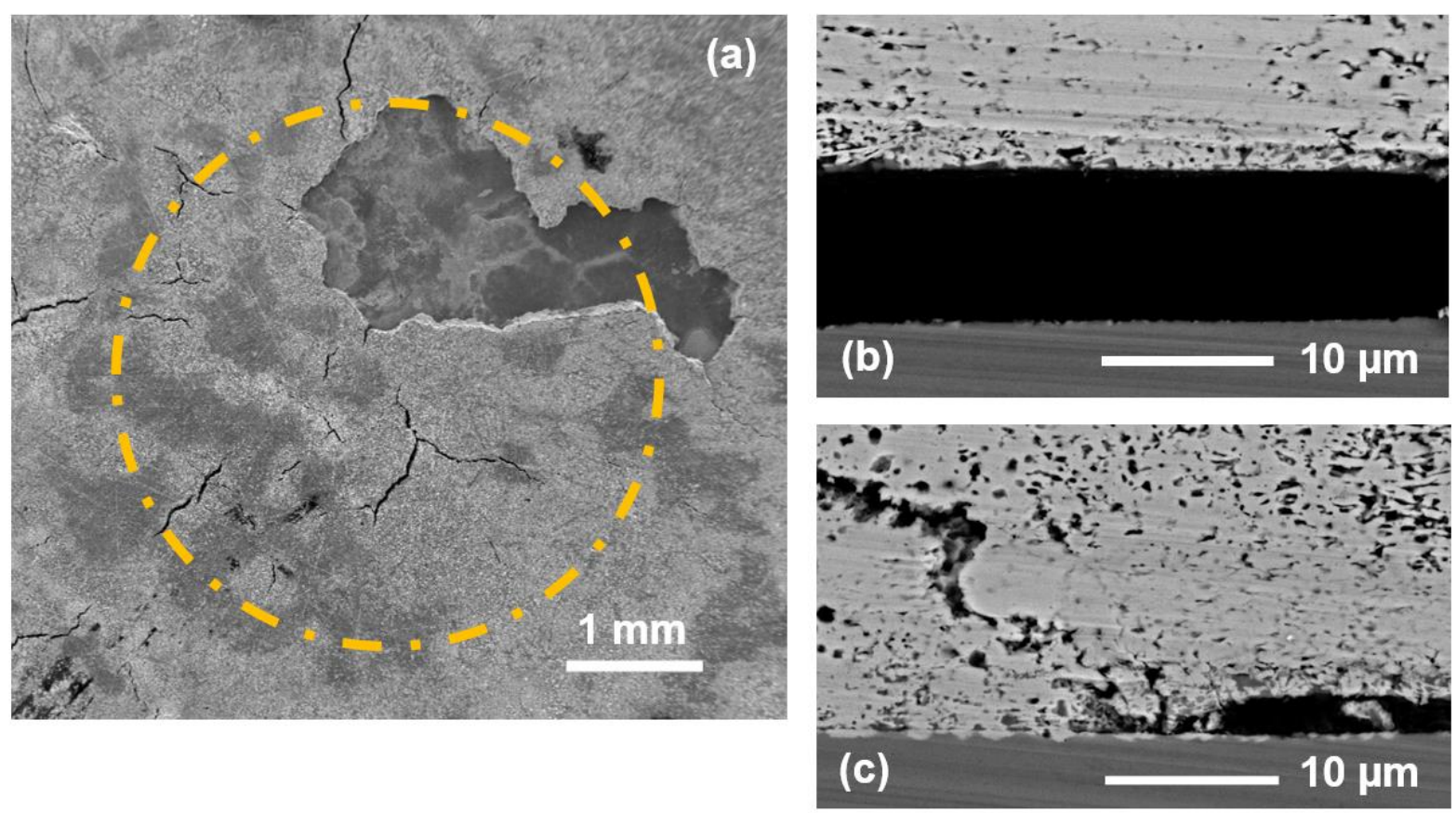

Figure 14. Scanning electron micrographs of a recovered sample showing the partial removal of a $90 \mu \mathrm{m}$-thick Ag layer, aged $840 \mathrm{~h}$, from a $1 \mathrm{~mm}$-thick Cu substrate subjected to laser shock loading. Most of this layer is still attached onto the substrate, except for an upper right zone in the loaded disk (a). Back scattering electron micrographs along a section across the loaded area show either full separation between both constituents (b) or segments of intact interface, probably strengthened by atomic diffusion during aging (c).

\section{Summary and conclusion}

Laser driven shocks were performed to test the bonding strength of sintered $\mathrm{Ag}$ on $\mathrm{Cu}$ substrates, both prior to and after aging, in the application context of power electronics modules. The pressure load was calibrated, dynamic tension was successfully induced near the $\mathrm{Cu}-\mathrm{Ag}$ interface, and extensive removal of the Ag layer was achieved. Although time-resolved free surface velocity measurements exhibit characteristic features associated with interface failure, thorough analysis and numerical simulations show that such features cannot directly provide estimates of the bonding strength yet. Indeed, quantitative interpretations would require accurate control of the Ag thickness and refined constitutive models accounting for porosity, pore collapse and subsequent dissipation. Nevertheless, post-shock observations of the fracture surface morphology in recovered samples provide some insight into the debonding mechanisms and their strong dependence on aging effects. Thus, the interface strength after aging seems to become much more spatially variant (i.e. variable over the tested area) than in as-sintered samples, due to, in some zones, a strengthening effect of both $\mathrm{Cu}$ oxide growing within the $\mathrm{Ag}$ layer and $\mathrm{Ag}$ grain growing within the $\mathrm{Cu}$ substrate, and, in nearby zones, the weakening effect of pores developing at the interface during diffusion of $\mathrm{Cu}$ into $\mathrm{Cu}$ oxide. Further work has been planned to explore the possible role of the underlying $\mathrm{Cu}$ microstructure on both effects. 


\section{Acknowledgments}

We thank Amélie Caradec, Florence Hamon and Dr. Dominique Eyidi (Institut Pprime, UPR 3346 CNRS) for their kind support in microscopy, as well as Anna Gordun and Kokouvi Happy N'Tsouaglo for helpful assistance in sample preparation. This work was partially funded by the French Government programs "Investissements d'Avenir" LABEX INTERACTIFS (reference ANR-11-LABX-0017-01).

\section{Disclosure statement}

We have no potential conflict of interest.

\section{References}

[1] Siow KS. Mechanical properties of nano-silver joints as die attach materials. J Alloy Compd. 2012; 514:6-19.

[2] Khazaka R, Mendizabal L, Henry D. Review on joint shear strength of nano-silver paste and its long-term high temperature reliability. J Elec Mat. 2014; 43:2459-2466.

[3] Chua T, Siow KS. Microstructural studies and bonding strength of pressureless sintered nano-silver joints on silver, direct bond copper (DBC) and copper substrates aged at 300 C. J Alloys Comp. 2016; 687:486-498.

[4] Zhang Z, Chen C, Yang Y, et al. Low-temperature and pressureless sinter joining of $\mathrm{Cu}$ with micron/submicron Ag particle paste in air. J Alloys Comp. 2019; 780:435-442.

[5] Siow KS, Chua ST, Beake BD, et al. Influence of sintering environment on silver sintered on copper substrate. J Mater Sci: Mat Electron. 2019; 30:6212-6223.

[6] Du CJ, Li X, Mei YH, et al. An explanation of sintered silver bonding formation on bare copper substrate in air. App Surf Sci. 2019; 490(1):403-410.

[7] Vossen JL. Measurements of film-substrate bond strength by laser spallation. Adhesion Measurement of thin Films, Thick Films and Bulk Coatings. Am Soc Test Mater. 1978; 640:122-133.

[8] Yuan J, Gupta V. Measurement of interface strength by the modified laser spallation technique. Experiment and simulation of the spallation process. J Appl Phys. 1993; 74(4):2388-2396.

[9] Boustie M, Auroux E, Romain JP, et al. Determination of the bond strength of some microns coatings using the laser shock technique. Eur Phys J A P. 1999; 5(2):149-153.

[10] Baumung K, Müller G, Singer J, et al. Strength of plasma sprayed turbine-blade coatings using an advanced spallation technique. J Appl Phys. 2001; 89(11): 6523-6529. 
[11] Arrigoni M, Barradas S, Braccini M, et al. A comparative study of three adhesion tests (EN 582, similar to ASTM C633, LASAT (LASer Adhesion Test), and bulge and blister test) performed on plasma sprayed copper deposited on aluminium 2017 substrates. J Adhes Sci Technol. 2006; 20(5):471-487.

[12] Wang X, Gupta V. Measurement of the intrinsic strength and intrinsic and total fracture resistances of stainless steel/E-glass composite joints. J Adhes Sci Technol. 2006; 20(11):1171-1188.

[13] Jain A, Youssef G, Gupta, V. Dynamic tensile strength of polyurea-bonded steel/E-glass composite joints. J Adhes Sci Technol. 2013; 27(4):403-412.

[14] Kim H, Tian J, Gupta V. In-situ measurement of solder joint strength in board-mounted chip-scale packages using a quantitative laser spallation technique. J Adhes Sci Technol. $2013 ; 27(7): 719-730$.

[15] Tian J, Kim H, Gupta V. Measurement of solder joint strength in freestanding chip-scale packages using a quantitative laser spallation technique. J Adhes Sci Technol. 2013; 27(8):835-842.

[16] Ehsani H, Boyd JD, Wang J, et al. Evolution of the laser-induced spallation technique in film adhesion measurement. Appl Mech Rev. 2021; 73:030802.

[17] de Rességuier T. On the shock-based determination of the adhesive strength at a substrate-coating interface. J Adhes Sci Technol. 2018; 32:36-49.

[18] Milhet X, Gadaud P, Caccuri V, et al. Influence of the porous microstructure on the elastic properties of sintered $\mathrm{Ag}$ paste as replacement material for die attachment. J Elec Mater. 2015; 44:3948.

[19] Gadaud P, Caccuri V, Bertheau D, et al. Ageing sintered silver: relationship between tensile behavior, mechanical properties and the nanoporous structure evolution. Mater Sci Eng A. 2016; 669:379-386.

[20] Milhet X, Nait-Ali A, Tandiang D, et al. Evolution of the nanoporous microstructure of sintered Ag at high temperature using in-situ X-ray nanotomography. Acta Mater. 2018; 156:310-317.

[21] Eliezer S, Gilath I, Bar-Noy T. Laser-induced spall in metals: experiment and simulation. J Appl Phys. 1990; 67:715.

[22] Benuzzi A, Löwer T, Koenig M, et al. Indirect and direct laser driven shock waves and applications to copper equation of state measurements in the 10-40 Mbar pressure range. Phys Rev E. 1996; 54(2):2162.

[23] Tollier L, Fabbro R. Study of the laser-driven spallation process by the VISAR interferometry technique. J Appl Phys. 1998; 83:1231.

[24] Kalantar DH, Belak JF, Collins GW, et al. Direct observation of the $\alpha-\varepsilon$ transition in shock-compressed iron via nanosecond X-ray diffraction. Phys Rev Lett. 2005; 95(7):075502. 
[25] de Rességuier T, Hallouin M. Effects of the $\alpha-\varepsilon$ phase transition on wave propagation and spallation in laser shock-loaded iron. Phys Rev B. 2008; 77(17):174107.

[26] Lescoute E, de Rességuier T, Chevalier JM, et al. Ejection of spalled layers from laser shock-loaded metals. J Appl Phys. 2010; 108(9):093510.

[27] de Rességuier T, Lescoute E, Loison D. Influence of elevated temperature on stress wave propagation and spallation in laser shock-loaded iron. Phys Rev B. 2012; 86(21):214102.

[28] de Rességuier T, Lescoute E, Sollier A, et al. Microjetting from grooved surfaces in metallic samples subjected to laser driven shocks. J Appl Phys. 2014; 115(4):043525.

[29] Remington TP, Remington BA, Hahn EN, et al. Deformation and failure in extreme regimes by high-energy pulsed lasers: a review. Mat Sci Eng A. 2017; 688:429-458.

[30] de Rességuier T, Hemery S, Lescoute E, et al. Spall fracture and twinning in laser shock-loaded single-crystal magnesium. J Appl Phys. 2017; 121(16):165104.

[31] Laurençon M, de Rességuier T, Loison D, et al. Effects of additive manufacturing on the dynamic response of AlSi10Mg to laser shock loading. Mat. Sci. Eng. A. 2019; 748:407-417.

[32] Prudhomme G., de Rességuier T, Roland C. et al. Velocity and mass density of the ejecta produced from sinusoidal grooves in laser shock-loaded tin. J. Appl. Phys. 2020; 128(15): 155903.

[33] Righi G., Ruestes C.J., Stan C.V., et al. Towards the ultimate strength of iron : spalling through laser shock. Acta Materialia. 2021; 215:117072.

[34] Fabbro R, Fournier J, Ballard P, et al. Physical study of laser-produced plasma in confined geometry. J Appl Phys. 1990; 68:775-784.

[35] Berthe L, Fabbro R, Peyre P, et al. Shock waves from a water-confined laser-generated plasma. J Appl Phys. 1997; 82:2826-2832.

[36] Barker LM, Hollenbach RE. Laser interferometer for measuring high velocities of any reflecting surface. J Appl Phys. 1972; 43:4669-4675.

[37] Hemsing WF. Velocity sensing interferometer (VISAR) modification. Rev Sci Instrum. 1979; 50:73-78.

[38] Altair Hyperworks. http://www.altairhyperworks.com/

[39] Meyers MA. Dynamic behavior of materials, ed. J. Wiley, New York. 1994.

[40] LASL Shock Hugoniot Data, ed. S.P. Marsh, University of California Press. 1980.

[41] Grady DE. The spall strength of condensed matter. J Mech Phys Solids. 1988; 36:353384.

[42] Antoun T, Seaman L, Curran DR, et al. Spall Fracture, Springer, New York. 2002. 
[43] Davison L, Horie Y, Shahinpoor M. High-pressure shock compression of solids IV: Response of highly porous solids to shock loading, Springer-Verlag New-York Inc. 1997.

[44] Lin YC, Liu X, Chou KW, et al. Unveiling 3D morphology of multiscale micronanosilver sintering for advanced electronics manufacturing by ptychographic X-ray nanotomography. Adv Eng Mat. 2020; 2(4):1901250. 